\title{
Development of specific PCR assays for the detection of Cryptocaryon irritans
}

\author{
W. Chen • H. Y. Sun • M. Q. Xie • J. S. Bai • X. Q. Zhu • \\ A. X. Li
}

Received: 27 January 2008 / Accepted: 7 April 2008/Published online: 9 May 2008

(C) The Author(s) 2008

\begin{abstract}
Cryptocaryon irritans is one of the most important protozoan pathogens of marine fish, causing the "white spot" disease and posing a significant problem to marine aquaculture. In the present study, a $C$. irritans-specific reverse primer (S15) was designed based on the published sequence of the second internal transcribed spacer (ITS-2) of ribosomal DNA (rDNA) of $C$. irritans and used together with the conserved forward primer P1 to develop a specific polymerase chain reaction (PCR) assay for direct, rapid, and specific detection of $C$. irritans. The specificity of these primers was tested with both closely and distantly related ciliates (Pseudokeroronpsis rubra, Pseudokeroronpsis carnae, Euplotes sp. 1, Ichthyophthirius multifiliis, Pseudourostyla cristata, and Paramecium caudaium), and only C. irritans was detected and no product was amplified from any other ciliates examined in this study using the specific primer set P1-S15. The specific PCR assay was able to detect as low as $45 \mathrm{pg}$ of $C$. irritans DNA and a nested PCR assay using two primer sets (P1/NC2, P1/S15)
\end{abstract}

W Chen and H Y Sun contributed equally to this work.

W. Chen · H. Y. Sun • M. Q. Xie · J. S. Bai • A. X. Li $(\bowtie)$

State Key Laboratory of Biocontrol, School of Life Sciences, Sun Yat-sen University,

135 Xingang West Street, Haizhu District,

Guangzhou, Guangdong Province 510275,

People's Republic of China

e-mail: anxing_li2002@yahoo.com.cn

X. Q. Zhu

College of Veterinary Medicine,

South China Agricultural University,

483 Wushan Street, Tianhe District,

Guangzhou, Guangdong Province 510642,

People's Republic of China

e-mail: xingquanzh@scau.edu.cn increased the sensitivity, allowing the detection of a single C. irritans. The species-specific PCR assays should provide useful tools for the diagnosis, prevention, and molecular epidemiological investigations of $C$. irritans infection in marine fish.

\section{Introduction}

Cryptocaryon irritans is one of the most important protozoan pathogens of marine fish, causing the white spot disease and posing a significant problem to marine aquaculture due to its widespread distribution, indiscriminate host specificity, and high level of virulence (Cheung et al. 1980; Yoshinaga and Dickerson 1994; Burgess and Matthews 1995; Diggles and Lester 1996a; Colorni and Burgess 1997; Jee et al. 2000; Hirazawa et al. 2001; Yambot et al. 2003; Luo et al. 2007). It invades the skin, eyes, and gills of marine fish, impairing the physiological function of these organs. C. irritans is capable of killing large numbers of fish in a short time and has a serious impact on aquaculture.

The conventional approaches for the detection and diagnosis of $C$. irritans infection include morphological identification and histopathology (Colorni 1985, 1987; Xu et al. 1995a, b; Diggles and Lester 1996b, c; Diggles 1997), but these methods have limitations in that they cannot differentiate closely related taxa such as $C$. irritans and Ichthyophthirius multifiliis. A range of studies have demonstrated that polymerase chain reaction (PCR)-based approaches, utilizing the first and/or second internal transcribed spacers of nuclear ribosomal DNA (ITS-1 and ITS-2), can be used for species-specific identification and detection of a number of parasite groups (Solaiman et al. 2000; Zhu et al. 2000; Furuya et al. 2002; Zhu et al. 2002; 
Table 1 Cryptocaryon irritans and other ciliate samples used in this study

\begin{tabular}{ll}
\hline Species & Source \\
\hline Cryptocaryon irritans & Our own laboratory \\
Pseudokeroronpsis rubra & ARLOUC \\
Pseudokeroronpsis carnae & ARLOUC \\
Pseudokeroronpsis flava & ARLOUC \\
Euplotes sp. 1 & MBSIOC \\
Ichthyophthirius multifiliis & DMMPUGAGA30602-7371 \\
Pseudourostyla cristata & SKLBSLSSYU \\
Paramecium caudaium & SKLBSLSSYU \\
\hline
\end{tabular}

ARLOUC Aquaculture Research Laboratory, China Ocean University; MBSIOC Marine Biological Specimen Museum, Institute of Oceanology, Chinese Academy of Sciences; DMMPUGAGA30602-7371 Departments of Medical Microbiology and Parasitology, University of Georgia, Athens, GA 30602-7371, USA; SKLBSLSSYU State Key Laboratory of Biocontrol, School of Life Sciences, Sun Yat-sen University

Huang et al. 2004; Traversa et al. 2004; Liu et al. 2006; Yoshida et al. 2006; Zhu et al. 2007). Recent studies have demonstrated that intra-specific variation in the ITS rDNA among C. irritans isolates was low (Diggles and Adlard 1997; Sun et al. 2006) and that the ITS sequence of $C$. irritans was significantly different from that of I. multifiliis, indicating that the ITS sequence also provides speciesspecific markers for the development of diagnostic assay for C. irritans (Sun et al. 2006).

This information provided a basis for the present study, the objective of which was to develop specific PCR assays, targeting the ITS rDNA region for the specific detection and diagnosis of $C$. irritans infections in marine fish.

\section{Materials and methods}

\section{Ciliate samples and DNA extraction}

The $C$. irritans used in the present study was maintained by serial passage on Traohinotinae ovatns in our laboratory (Dan et al. 2006). Other ciliates were obtained from several other laboratories shown in Table 1. The ciliate samples used were suspended in $70 \%$ ethanol and stored at $-20^{\circ} \mathrm{C}$ until required for DNA extraction.

Genomic DNA was extracted as described previously (Li et al. 2005; Sun et al. 2006). DNA samples were stored at $-20^{\circ} \mathrm{C}$ until PCR amplification. Genomic DNA from single C. irritans was obtained using the following freeze-thawing protocol. Individual $C$. irritans were placed in clean Eppendorf tubes, and then the Eppendorf tubes were plunged into liquid nitrogen for $3 \mathrm{~min}$, and then thawed rapidly in $84-94^{\circ} \mathrm{C}$ water bath for $3 \mathrm{~min}$. Then the tubes were immediately replaced to liquid nitrogen for $3 \mathrm{~min}$. This freeze-thawing step was repeated three times. Then the liquid in the tube was used for PCR amplification directly.

Design of species-specific primers and optimization of specific PCR assays

Based on the comparison of the ITS-1 and ITS-2 sequences of $C$. irritans with that of other related ciliates, a speciesspecific reverse primer, S15, was designed between sequence positions 45-69 bp in the ITS-2 for C. irritans (Fig. 2 in Sun et al. 2006; also see GenBank ${ }^{\mathrm{TM}}$ accession numbers DQ270008-270014). This primer was used with the conserved forward primer P1 to amplify the partial 18S, ITS-1, 5.8S rDNA, and the partial ITS-2 of C. irritans, expecting to produce a DNA fragment of $541 \mathrm{bp}$. Similarly, for I. multifiliis, a specific forward primer S01 was designed in the ITS-1 (sequence positions 159-181 bp), a reverse specific primer S02 was designed in the ITS-2 (sequence positions 33-57 bp) (Fig. 2 in Sun et al. 2006; also see GenBank ${ }^{\mathrm{TM}}$ accession numbers DQ270015270016) to amplify the partial ITS-1, complete 5.8S rDNA, and partial ITS-2, and the length of the amplified DNA fragment was estimated to be $280 \mathrm{bp}$. PCR primers used in this study are listed in Table 2.

The PCR conditions for specific amplification of $C$. irritans ITS rDNA were optimized for specificity by varying the annealing temperatures and magnesium concentrations. The $C$. irritans-specific primer set was also evaluated for its specificity using heterogeneous species of ciliates (Table 1) as controls. The specificity of one representative amplicon produced using the $C$. irritansspecific primer set was verified by directly sequencing it.
Table 2 PCR primers used in this study

\begin{tabular}{lll}
\hline Primer name & Sequence & Reference \\
\hline P1 & 5'-GTTCCCCTTGAACGAGGAATTC-3' & Yoshinaga and Dickerson 1994 \\
NC2 & 5'-TTAGTTTCTTTTCCTCCGCT-3' & Sun et al. 2006 \\
S15 & 5'-TGAGAGAATTAATCATAATTTATAT-3' & The present study \\
S01 & 5'-GTACTTTATTTAGGAGGAGGACT-3' & The present study \\
S02 & 5'-TGTTTAACGAGAGAAAATCATAAAT-3' & The present study \\
\hline
\end{tabular}


Specific amplification of ITS rDNA

To verify the efficacy of the genomic DNA isolated from the "control" ciliates and clinical isolates (Table 1), PCR was performed to amplify the ITS and 5.8S rDNA plus primer flanking $18 \mathrm{~S}$ and $28 \mathrm{~S}$ rDNA sequences using the universal primer set P1/NC2 (Sun et al. 2006).

For the specific amplification of ITS rDNA from $C$. irritans, PCR reaction was performed in a final volume of $50 \mu 1$ containing template DNA, $10 \mathrm{mM}$ Tris- $\mathrm{HCl}, 50 \mathrm{mM}$ $\mathrm{KCl}, 3 \mathrm{mM} \mathrm{MgCl}{ }_{2}, 200 \mu \mathrm{M}$ dNTPs, 0.5 pmol of each primer, and $2.5 \mathrm{U} \mathrm{Taq}$ polymerase (Takara) in a thermocycler (Biometra) under the following optimized amplification conditions: an initial denaturation at $94^{\circ} \mathrm{C}$ for $5 \mathrm{~min}$, followed by 35 cycles of $94^{\circ} \mathrm{C}$ for $30 \mathrm{~s}$ (denaturation); $53^{\circ} \mathrm{C}$ for $30 \mathrm{~s}$ (annealing) and $72^{\circ} \mathrm{C}$ for $1.5 \mathrm{~min}$ (extension), followed by a final extension at $72^{\circ} \mathrm{C}$ for $5 \mathrm{~min}$. Two microliters (5-10 ng) of genomic DNA was added to each PCR reaction. Samples with host (fish) DNA and without DNA (no-DNA controls) were included in each PCR run as controls. An aliquot $(5 \mu \mathrm{l})$ of each amplicon was examined in $1 \%$ agarose gels, stained with ethidium bromide, and photographed using a gel documentation system (UVItec).

\section{Determination of sensitivity for the specific PCR assay}

The sensitivity of the specific PCR assay for C. irritans was estimated by serial dilution of genomic DNA from pooled $C$. irritans. To evaluate the efficiency of the C. irritansspecific PCR assay for the detection of individual $C$. irritans, DNA from single $C$. irritans was obtained by the freeze-thawing protocol and then it was used for nested PCR amplification as following. Firstly, the DNA samples were subjected to a conventional PCR amplification using primer set $\mathrm{P} 1 / \mathrm{NC} 2$ and $1 \mu \mathrm{l}$ of the primary amplicon was subjected to a second PCR amplification using the specific primer set $\mathrm{P} 1 / \mathrm{S} 15$. The experiment was repeated three times.

Detection of $C$. irritans from infected water by specific PCR assay

To evaluate whether the specific PCR assay could detect $C$. irritans in the infected seawater, a simulation protocol was carried out in the laboratory. Healthy fish free of $C$. irritans were exposed to $C$. irritans infections and the fish were successfully infected. Then, $1,000 \mathrm{ml}$ seawater was randomly collected from the tank containing the infected fish. The water was firstly filtrated with a 300 mesh sieve to remove the impurity, $1 \mathrm{ppm}$ formalin was added into the water to kill $C$. irritans, and then the $C$. irritans was harvested by centrifugation at $10,000 \mathrm{rpm}$ for $5 \mathrm{~min}$. The supernatant was removed and the pelleted material was used for DNA extraction as described above, following the freeze-thawing protocol. Then the extracted DNA was used for amplication by the nested PCR protocol. The uninfected seawater was used as negative control.

\section{Results and discussion}

As expected, the conserved primer set $\mathrm{P} 1 / \mathrm{NC} 2$ primers amplified ITS rDNA from all of the samples used in the present study (Table 1), but no amplicons were obtained from fish DNA (Fig. 1a).

The specific PCR protocols achieved optimality by varying the annealing temperatures and titrating the magnesium concentrations. The optimal annealing temperature was $53^{\circ} \mathrm{C}$ and the optimal magnesium concentration was $3 \mathrm{mM}$ for the $C$. irritans-specific PCR assay.

By using C. irritans-specific primer set $\mathrm{P} 1 / \mathrm{S} 15$ under optimized conditions, an amplification product of the expected size (approximately $540 \mathrm{bp}$ ) was amplified from C. irritans DNA (Fig. 1b). No amplification products were observed from any other DNA samples and from negative control containing no DNA.

\section{a}

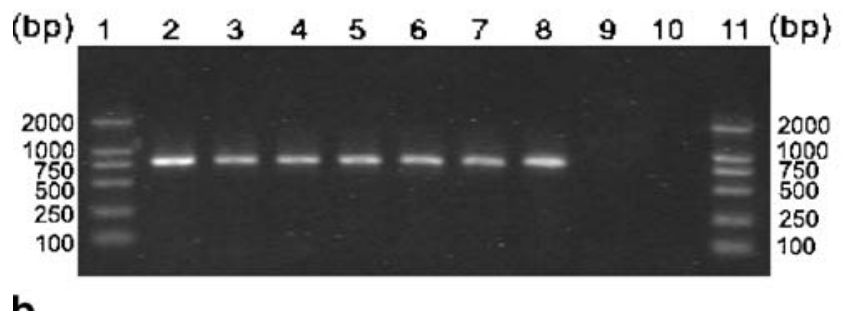

b

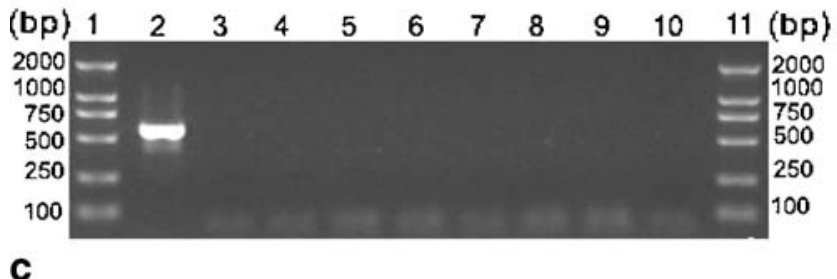

C

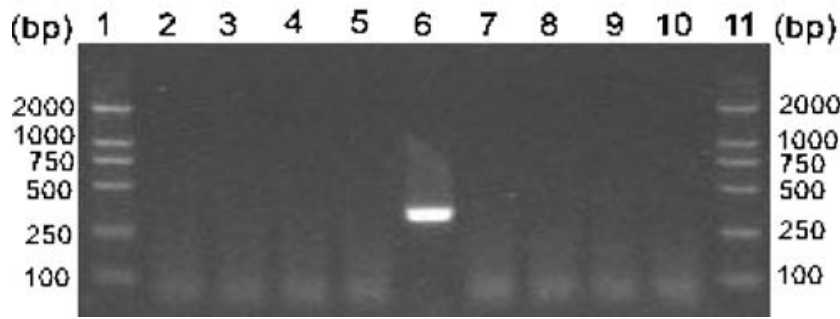

Fig 1 Agarose gel electrophoresis of PCR products amplified using conserved primer set $\mathrm{P} 1 / \mathrm{NC} 2$ (a), Cryptocaryon irritans-specific primer set P1/S15 (b), and Ichthyophthirius multifiliis-specific primer set S01/S02 (c). Lanes 1 and 11 represent a DNA size marker. Lanes 2 to 9 represent $C$. irritans, Pseudokeroronpsis rubra, Pseudokeroronpsis carnae, Euplotes sp. 1, I. multifiliis, Pseudourostyla cristata, Paramecium caudaium (cf. Table 1), and host (fish) DNA, respectively. Lane 10 represents no-DNA control 
Given that I. multifiliis causes white spot disease in fresh water fish, which is quite similar to that in marine fish caused by $C$. irritans, a specific primer set $\mathrm{S} 01 / \mathrm{S} 02$ for $I$. multifiliis was also designed and this primer set amplified DNA from I. multifiliis only (Fig. 1c).

To mimic the natural actual condition, a mixture of $C$. irritans and I. multifiliis DNA was used as template to evaluate the specific primers for $C$. irritans and I. multifiliis. A clear band of approximately $540 \mathrm{bp}$ was produced for $C$. irritans only and another band of approximately $280 \mathrm{bp}$ for $I$. multifiliis (Fig. 2), demonstrating that the established specific PCR assays could differentiate $C$. irritans from $I$. multifiliis.

One representative amplicon produced using the specific PCR primer set for $C$. irritans was sequenced with corresponding primers and proved to be partial ITS of $C$. irritans (data not shown), demonstrating the specificity of the primers, cycling conditions, and the PCR. The smallest amount of DNA detectable for C. irritans-specific PCR assay was 45 pg (Fig. 3) and the nested PCR assay could detect DNA from single $C$. irritans following the freezethawing protocol (not shown).

The specific PCR assay was then used to detect $C$. irritans contained in the infected seawater simulated in the laboratory. As shown in Fig. 4, specific PCR products were amplified from all of the six infected water bodies examined by the nested PCR and no products were obtained from the negative and no-DNA controls. These findings demonstrated that the PCR assays for $C$. irritans were specific and sensitive, allowing the detection of single C. irritans.

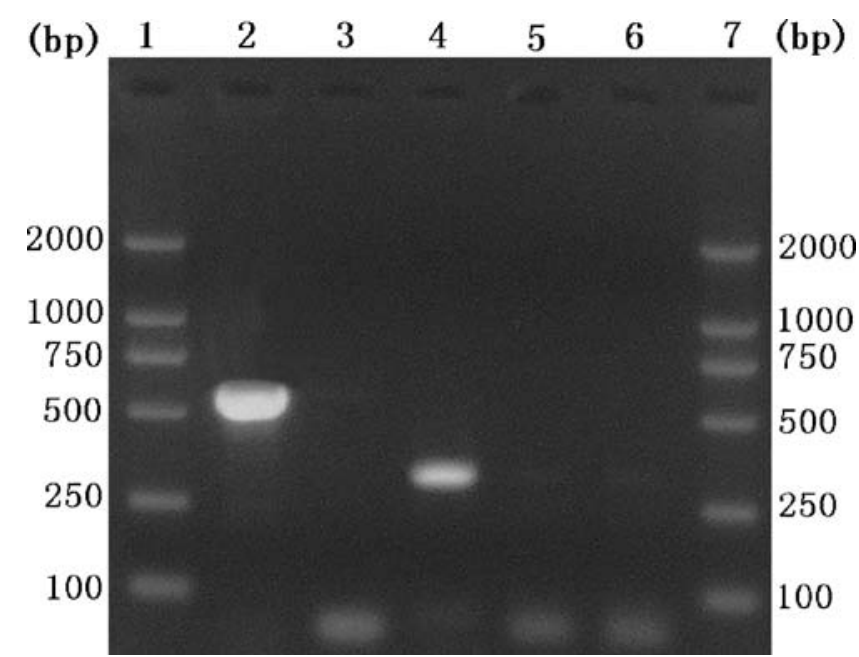

Fig 2 Agarose gel electrophoresis of PCR products amplified from mixed genomic DNA of $C$. irritans and I. multifiliis. Lanes 1 and 7 represent a DNA size marker. Lane 2 presents the mixture of $C$. irritans and I. multifiliis DNA amplified using the primer set $\mathrm{P} 1 / \mathrm{S} 15$ and lane 3 represents the genomic DNA of $I$. multifiliis. Lane 4 represents the mixed genomic DNA of C. irritans and I. multifiliis amplified using the primer set S01-S02. Lane 5 represents the genomic DNA of $C$. irritans using the primer set $\mathrm{S} 01-\mathrm{S} 02$. Lane 6 represents no-DNA control

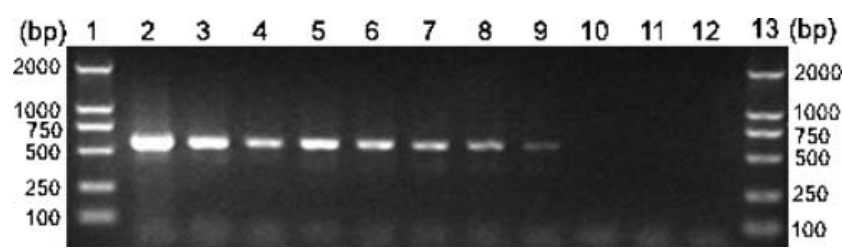

Fig 3 Evaluation of the sensitivity of the specific PCR assay for Cryptocaryon irritans (primer set P1/S15) by agarose gel electrophoresis. Lanes 1 and 13 represent a DNA size marker. Lane 2 represents DNA undiluted $(450 \mathrm{ng} / \mu \mathrm{l})$, and lanes 3 to 11 represent $C$. irritans DNA diluted for 1:50 $(9 \mathrm{ng} / \mu \mathrm{l}), 1: 100(4.5 \mathrm{ng} / \mu \mathrm{l}), 1: 200(2.25 \mathrm{ng} / \mu \mathrm{l})$,

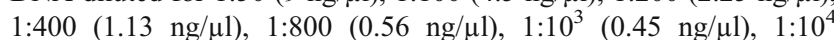
(45 pg/ $/ \mu 1), 1: 10^{5}(4.5 \mathrm{pg} / \mu \mathrm{l})$, and $1: 10^{6}(0.45 \mathrm{pg} / \mu \mathrm{l})$, respectively. Lane 12 represents no-DNA control

Primer design is the crucial step in the development of PCR assays for the specific identification and detection of parasites. In the present study, the specific reverse primer for $C$. irritans was designed in the ITS-2 based on its published ITS sequences, because previous studies have proven that ITS sequences provide reliable species-specific markers for a range of parasites groups. The results reported herein clearly demonstrated that the $C$. irritans-specific primer pair was able to distinguish $C$. irritans from other closely related ciliates.

To ensure the sufficient sensitivity of the specific PCR assay, a nested approach was adopted for the detection of single $C$. irritans and for $C$. irritans in infected seawater. For this purpose, the ITS rDNA was firstly amplified by the conserved primer set $\mathrm{P} 1 / \mathrm{NC} 2$, followed by secondary amplification of the primary amplicon by the specific primer set $\mathrm{P} 1 / \mathrm{S} 15$. This nested approach allowed the detection of single $C$. irritans.

The white spot disease caused by $C$. irritans is considered the most important parasitic disease of marine fish. It is well known that $C$. irritans increases by orders of magnitude with each round of replication and its life cycle is a direct one requiring no intermediate host, which can quickly overwhelm fish in a few days under mariculture. Given the significant importance of $C$. irritans infection in fish health and mariculture, rapid identification of the pathogen is the prerequisite for the diagnosis and prevention of further spread of the infection. Therefore, the established

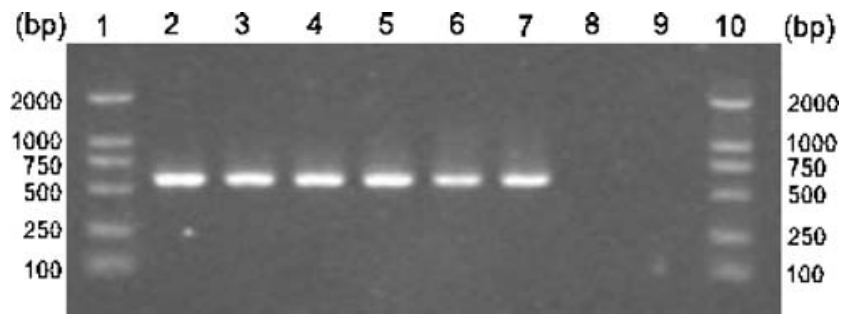

Fig 4 Agarose gel electrophoresis of PCR products amplified from the simulated water body using Cryptocaryon irritans-specific primer set $\mathrm{P} 1 / \mathrm{S} 15$. Lanes 1 and 10 represent a DNA size marker, lanes 2 to 7 represent $C$. irritans from the infected water, lane 8 represents the uninfected water, and lane 9 represents no-DNA control 
specific PCR assays should provide useful tools for the accurate identification and detection of $C$. irritans infection.

In conclusion, the present study demonstrated that the specific (nested) PCR assays are useful for the identification and detection of $C$. irritans. They should provide rapid and reliable tools that can be used directly by diagnostic laboratories and should have important implications for the prevention and epidemiological investigation of $C$. irritans infections in marine fish.

Acknowledgements Project support was provided in part by grants from Key Projects in the National Science \& Technology Pillar Program in the Eleventh Five-year Plan Period (2007BAD29B05) and the Agricultural Science and Technology Programs from Guangdong Province (grant no. 2007B080701009) to AXL. The authors are grateful to Prof. Zheng Shouyi (Academician) and Prof. Xu Kuidong (Marine Biological Specimen Museum, Institute of Oceanology, Chinese Academy of Sciences), Prof. Song Weibo (Aquaculture Research Laboratory, China Ocean University), Prof. Harry W. Dickerson (Departments of Medical Microbiology and Parasitology, University of Georgia), and Dr. Huang Jianrong (State Key Laboratory of Biocontrol, School of Life Sciences, Sun Yat-sen University, China) for providing the "control" ciliate samples. The experiments comply with the current laws of the country in which the experiments were performed.

Open Access This article is distributed under the terms of the Creative Commons Attribution Noncommercial License which permits any noncommercial use, distribution, and reproduction in any medium, provided the original author(s) and source are credited.

\section{References}

Burgess PJ, Matthews RA (1995) Fish host range of seven isolates of Cryptocaryon irritans (Ciliophora). J Fish Biol 46:727-729

Cheung PJ, Nigrelli RF, Ruggieri GD (1980) Studies on cryptocaryoniasis in marine fish: effect of temperature and salinity on reproductive cycle of Cryptocaryon irritans Brown, 1951. J Fish Dis 2:93-97

Colorni A (1985) Aspects of the biology of Cryptocaryon irritans and hyposalinity as a control measure in cultured gilt-head sea bream Sparus aurata. Dis Aquat Org 1:19-22

Colorni A (1987) Biology of Cryptocaryon irritans and strategies for its control. Aquaculture 67:236-237

Colorni A, Burgess P (1997) Cryptocaryon irritans Brown 1951, the cause of 'white spot disease' in marine fish: an update. Aquar Sci Conserv 1:217-238

Dan XM, Li AX, Lin XT, Zhu XQ (2006) A standardized method to propagate Cryptocaryon irritans on a susceptible host pompano Trachinotus ovatus. Aquaculture 258:127-133

Diggles BK (1997) Some information on the morphology of Cryptocaryon irritans from South-East Queensland, Australia. Europ J Protistol 33:200-210

Diggles BK, Lester RJG (1996a) Influence of temperature and host species on the development of Cryptocaryon irritans. J Parasitol 82:45-51

Diggles BK, Lester RJG (1996b) Infections of Cryptocaryon irritans on wild fish from southeast Queensland, Australia. Dis Aquat Org 25:159-167

Diggles BK, Lester RJG (1996c) Variation in the development of two isolates of Cryptocaryon irritans. J Parasitol 82:384-388

Diggles BK, Adlard RD (1997) Intraspecific variation in Cryptocaryon irritans. J Eukaryot Microbiol 44:25-32
Furuya N, Ura H, Iiyama K, Matsumoto M, Takeshita M, Takanami Y (2002) Specific oligonucleotide primers based on sequences of the 16S-23S rDNA spacer region for the detection of Burkholderia gladioli by PCR. J Gen Plant Pathol 68:220-224

Hirazawa N, Oshima SI, Hara T, Mitsuboshi T, Hata K (2001) Antiparasitic effect of medium-chain fatty acids against the ciliate Cryptocaryon irritans infestation in the red sea bream Pagrus major. Aquaculture 198:219-228

Huang WY, He B, Wang CR, Zhu XQ (2004) Characterisation of Fasciola species from Mainland China by ITS-2 ribosomal DNA sequence. Vet Parasitol 120:75-83

Jee BY, Kim KH, Park SH, Kim YCh (2000) A new strain of Cryptocaryon irritans from the cultured olive flounder Paralichthys olivaceus. Dis Aquat Org 43:211-215

Li AX, Wu XY, Ding XJ, Lin RQ, Xie MQ, Lun ZR, Zhu XQ (2005) PCRSSCP as a molecular tool for the identification of Benedeniinae (Monogenea: Capsalidae) from marine fish. Mol Cell Probes 19:35-39

Liu Y, Gao Q, Zhang X, Hou Y, Yang J, Huang X (2006) PCR and oligonucleotide array for detection of Enterobacter sakazakii in infant formula. Mol Cell Probes 20:11-17

Luo XC, Xie MQ, Zhu XQ, Li AX (2007) Protective immunity in grouper (Epinephelus coioides) following exposure to or injection with Cryptocaryon irritans. Fish Shellfish Immunol 22:427-432

Solaiman DKY, Ashby RD, Foglia TA (2000) Rapid and specific identification of medium-chain-length polyhydroxyalkanoate synthase gene by polymerase chain reaction. Appl Microbiol Biotechnol 53:690-694

Sun XY, Zhu XQ, Xie MQ, Wu XY, Li AX, Lin RQ, Song HQ (2006) Characterization of Cryptocaryon irritans isolates from marine fishes in Mainland China by ITS ribosomal DNA sequences. Parasitol Res 99:160-166

Traversa D, Giangaspero A, Galli P, Paoletti B, Otranto D, Gasser RB (2004) Specific identification of Habronema microstoma and Habronema muscae (Spirurida, Habronematidae) by PCR using markers in ribosomal DNA. Mol Cell Probes 18:215-221

Xu RL, Bai QS, Li GS, Jiang JB (1995a) Ultrastructural study on tomite of Cryptocaryon irritans Brown, 1951. J Sun Yat-sen Univ (Suppl) 1:142-145 (in Chinese with abstract in English)

Xu RL, Bai QS, Li GS, Jiang JB (1995b) The host visceral histochemical changes caused by "white spot" disease in marine fishes. J Sun Yatsen Univ (Suppl) 1:146-148 (in Chinese with abstract in English)

Yambot AV, Song YL, Sung HH (2003) Characterization of Cryptocaryon irritans, a parasite isolated from marine fishes in Taiwan. Dis Aquat Org 54:147-156

Yoshinaga T, Dickerson HW (1994) Laboratory propagation of Cryptocaryon irritans Brown, 1951 on saltwater-adapted black mollies Poecilia latipinna. J Aquat Anim Health 6:197-201

Yoshida E, Makimura K, Mirhendi H, Kaneko T, Hiruma M, Kasai T, Uchida K, Yamaguchi H, Tsuboi R (2006) Rapid identification of Trichophyton tonsurans by specific PCR based on DNA sequences of nuclear ribosomal internal transcribed spacer (ITS) 1 region. J Dermatol Sci 42:225-230

Zhu XQ, D’Amelio S, Paggi L, Gasser RB (2000) Assessing sequence variation in the internal transcribed spacers of ribosomal DNA within and among members of the Contracaecum osculatum complex (Nematoda: Ascaridoidea: Anisakidae). Parasitol Res 86:677-683

Zhu XQ, D'Amelio S, Palm HW, Paggi L, George-Nascimento M, Gasser RB (2002) SSCP-based identification of members within the Pseudoterranova decipiens complex (Nematoda: Ascaridoidea: Anisakidae) using genetic markers in the internal transcribed spacers of ribosomal DNA. Parasitology 124:615-623

Zhu XQ, D'Amelio S, Gasser RB, Yang TB, Paggi L, He F, Lin RQ, Song HQ, Ai L, Li AX (2007) Practical PCR tools for the delineation of Contracaecum rudolphii $\mathrm{A}$ and Contracaecum rudolphii B (Ascaridoidea: Anisakidae) using genetic markers in nuclear ribosomal DNA. Mol Cell Probes 21:97-102 